\title{
A CASE OF PSEUDOANGIOEDEMA AS A SUPERIOR VENA CAVA SYNDROME
}

\author{
Sibel Berksoy Hayta ${ }^{1}$, Rukiye Güner ${ }^{1}$, Sulhattin Arslan ${ }^{2}$, Cesur Gümüşs ${ }^{3}$, Melih Akyol ${ }^{1}$
}

1Department of Dermatology, Cumhuriyet University School of Medicine, Sivas, Turkey.

2Department of Chest Diseases, Cumhuriyet University School of Medicine, Sivas, Turkey.

3Department of Radiology Cumhuriyet University School of Medicine, Sivas, Turkey.

Corresponding author: Dr. Sibel Berksoy Hayta, Dermatoloji Anabilim Dalı, Cumhuriyet Üniversitesi Tip Fakültesi, TR-58140, Sivas, Türkiye.

E-mail: drberksoy@gmail.com

Received/Accepted: October 06, 2015 / April 01, 2016

Conflict of interest: There is not a conflict of interest.

\section{Dear Editor}

43-year-old female patient was admitted to our clinic because of the swelling of the face and eyelids for two weeks. The patient was using some analgesics, including paracetamol. Her medical history included a cerebrovascular accident one year ago. There was a history of cough and dyspnea for a while. She was receiving an angioedema treatment with antihistaminic (pheniramine maleate) and methylprednisolone. The patient who did not respond this treatment was hospitalized. On physical examination, a diffuse erythematous swelling without telangiectases affected her face and neck. The remaining dermatologic examination was normal. She has not got any urticarial papules or plaques. She was mildly anemic (haemoglobin: $11.3 \mathrm{~g} / \mathrm{dL}$, haematocrit: 35,6), and her erythrocyte sedimentation rate was 40. Hepatitis B surface antigen was positive. Other routine haematologic analysis, urine analysis and IgE levels were normal.

The patient was consulted by a pulmonologist, and computed tomography (CT) of the chest disclosed a mediastinal mass that was compressing the superior vena cava (SVC) and multipl metastases, including liver and vertebrae (Figure 1a and b). Histopathologic examination of biopsy specimens obtained from the mass identified poorly differentiated adenocarcinoma of the lung. The patient was referred to oncology for chemotherapy. She died 4 months later. 


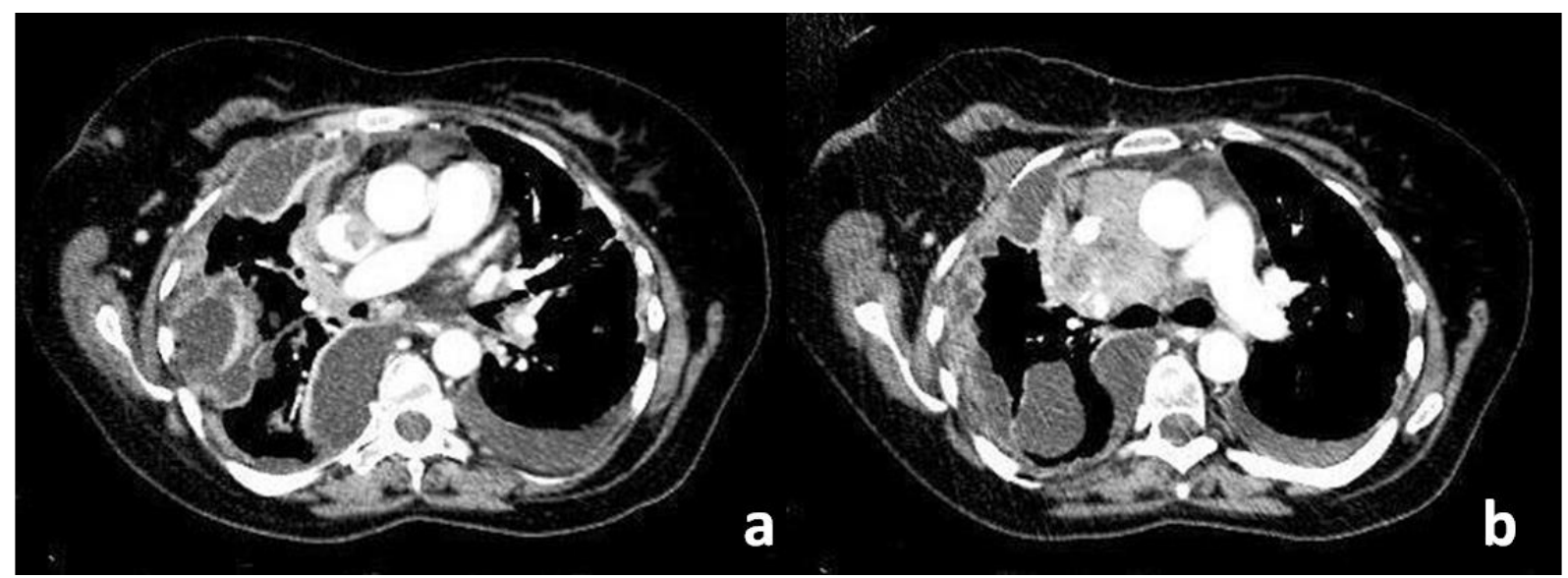

Figure 1: a) Right paratracheal mediastinal mass that was compressing the superior vena cava, and invading ascending aorta and right bronchus withpleural effusion, b) vena cava superior thrombosis, bilateral pleural effusion.

Angioedema is characterized by swelling just below the surface of the skin and/or mucosa, caused by a sudden increase in endothelial permeability with extravasation of intravascular fluid into the interstitial tissues. A variety of mechanisms can trigger the process, causing angioedema to be classified into two main categories: hereditary and acquired angioedema ${ }^{1-3}$ Unlike other forms of edema, angioedema is nonpitting, often asymmetric and has a tendency not to involve gravitationally dependent areas. The skin is usually normal in color, but can be slightly erythematous. The swelling is typically of slow onset over several hours and lasts for $>72 \mathrm{~h}$ resolving spontaneously without staining or desquamation of the skin. ${ }^{4,5}$

When working in the clinical setting, it is essential to remember that not all swellings are angioedema $^{1,6,7}$.

There are several conditions presenting with subcutaneous swelling that superficially resemble angioedema. Based on key signs and symptoms (Acute contact dermatitis, drug rash with eosinophilia and systemic symptoms, dermatomyositis, morbus morbihan, superior vena cava syndrome, hypothyroidism, subcutaneous emphysema, orofacial granulomatosis, hypocomplementemic urticarial vasculitis syndrome, Clarkson's disease, cluster headache, Gleich's syndrome, idiopathic edema), these socalled pseudoangioedemas can clinically be distinguished from true angioedema. Misdiagnosis may lead to ineffective management of these potentially serious conditions, as most do not respond to conventional angioedema treatment, making a correct determination of the root causes of symptoms essential and, in some cases, even life-saving. An understanding of clinical features unique to angioedema as well as its differential diagnosis, is therefore of great importance and will help the physician to target the correct underlying pathophysiology. Syndromes that masquerade as angioedema are referred to as pseudoangioedemas in the literature and should be considered in any patient presenting with atypical manifestations 1,7 .

Superior vena cava syndrome (SVCS) is the clinical presentation of superior vena cava obstruction (SVCO), or severe reduction in venous return from the head, neck, and upper extremities. William Hunter in 1757, is generally given credit for describing the first case of SVCS in a patient with an syphilitic aortic aneurysm obstructing the superior vena cava. Many benign or malignant conditions may cause obstruction of the superior vena cava either by external compression or local invasion, and some by intraluminal obstruction ${ }^{8}$. Common causes for masses that can impinge on the SVC include enlarged paratracheal lymph nodes of malignancies, lymphoma, thymoma, inflammatory processes, and aortic aneurysms. In the past 20 years, intravascular devices such as catheters and pacemakers have become much more common. Despite the recent rise in thrombus-driven SVCS, malignancies remain the most common cause 
of SVCS. Among the malignant causes of SVCS, non-small cell lung cancer (22-57 \%), small-cell lung cancer (10-39 \%), and lymphoma (1-27 \%) are by far the most common causes ${ }^{9}$.

The SVC is responsible for one-third of the body's venous return Thus SVCO is a medical emergency, as it causes impairment of the venous return to the heart, reducing the volume of blood available for the heart to pump effectively around the body. In addition to the hydrostatic back-pressure generated, the flow of deoxygenated blood is impaired, causing carbon-dioxide concentrations in the affected veins to climb, thus producing cerebral oedema and resulting headache, confusion and coma. Symptoms are usually insidious ${ }^{10}$. In addition to swelling and skin flushing of the areas drained by the SVC, including the arms, chest, head and neck, breathlessness is a common presenting symptom, and the physical features in the later stages mimic angio-oedema. However, the major difference is that angiooedema symptoms are often episodic, whereas SVCO is characteristically persistent and progressive $^{8,11}$.

Prognosis and treatment of SVCS will necessarily be determined by the cause of the syndrome. It is therefore recommended that patients presenting with SVCS should be carefully and promptly evaluated ${ }^{8}$.

We want to emphasize that, in dermatology policlinics, in patients with facial erithema and edema, superior vena cava syndrome which does not always come to our mind must be remembered. This case highlights the importance of considering other causes of facial swelling when assessing a patient with assumed allergy.

\section{REFERENCES}

1. Andersen MF, Longhurst HJ, Rasmussen ER, Bygum A. How Not to Be Misled by Disorders Mimicking Angioedema: A Review of Pseudoangioedema. Int Arch Allergy Immunol 2016; 169: 163-70.

2. Cicardi M, Aberer W, Banerji A, Bas M, Bernstein JA, Bork K, Caballero T, Farkas H, Grumach A, Kaplan AP, Riedl MA, Triggiani M, Zanichelli A, Zuraw B: Classification, diagnosis, and approach to treatment for angioedema: consensus report from the Hereditary Angioedema International Working Group. Allergy 2014; 69: 602-16.

3. Grigoriadou S, Longhurst HJ: Clinical immunology review series: an approach to the patient with angio-oedema. Clin Exp Immunol 2009; 155: 367-77.

4. Kaplan AP, Greaves MW: Angioedema. J Am Acad Dermatol 2005; 53: 373-88.

5. Frigas E, Nzeako UC: Angioedema. Clin Rev Allergy Immunol 2002; 23: 217-31.

6. Zingale LC, Beltrami L, Zanichelli A, Maggioni L, Pappalardo E, Cicardi B, Cicardi M: Angioedema without urticaria: a large clinical survey. CMAJ 2006; 175 : 1065-70.

7. Kakimoto C, Sparks C, White AA: Melkersson- Rosenthal syndrome: a form of pseudoangioedema. Ann Allergy Asthma Immunol 2007; 99: 185-9.

8. Jansen T, Romiti R, Messer G, Stücker M, altmeyer P. Superior vena cava syndrome presenting as persistent erythematous oedema of the face. Clin Exp Dermatol 2000; 23: 198-200.

9. Straka C, Ying J, Kong FM, Willey CD, Kaminski J, Kim DW. Review of evolving etiologies, implications and treatment strategies for the superior vena cava syndrome. Springerplus 2016; 5: 229.

10. Wilson L, Detterback F, Yahalom J et al. Superior vena cava syndrome with malignant causes. N Eng J Med 2007; 356: 1862-9.

11. Yong AS, Haque Hussain SS, Marrouche N, Grattan CE. Superior vena cava obstruction presenting as acute allergy. Clin Exp Dermatol 2013; 38: 955-6. 